\title{
Development of a TD-NMR Method to Monitor Brazil Nuts Oil Content: A Green and Low-Cost Based Approach
}

\author{
Úrsula A. Ribeiro, ${ }^{a}$ Leonardo C. Queiroz, ${ }^{a}$ Agide G. Marassi, ${ }^{\circ}{ }^{b}$ André S. Carvalho, ${ }^{b}$ \\ Gabriel A. Barros, ${ }^{a}$ Daniel M. Consalter, ${ }^{b}$ Jaqueline A. Bezerra, ${ }^{\oplus a, c}$ Alan D. C. Santos, ${ }^{\oplus *, a}$ \\ Luiz Alberto Colnago ${ }^{d}$ and Marcos B. Machado ${ }^{\circledR *, a}$
}

${ }^{a}$ Núcleo de Estudos Químicos de Micromoléculas da Amazônia (NEQUIMA), Av. Gen. Rodrigo Octávio Jordão Ramos, 1200, Setor Norte, ICE, Bloco 10, Coroado I, 69067-005 Manaus-AM, Brazil

${ }^{b}$ Fine Instrument Technology (FIT), Rua Laura Villani Piovesan, 130, Jardim Ipanema 1, 3563-652 São Carlos-SP, Brazil

'Instituto Federal de Educação, Ciência e Tecnologia do Amazonas (IFAM), Av. Sete de Setembro, 1975, Centro, 69020-120 Manaus-AM, Brazil

${ }^{d}$ Embrapa Instrumentação, Rua XV de Novembro, 1452, CP 741, 13560-970 São Carlos-SP, Brazil

\begin{abstract}
Growth in the international popularity of Brazil nuts oil (Bertholletia excelsa, Bonpl.) has demanded a closer look at quality aspects of the nuts. In this context, time-domain ${ }^{1} \mathrm{H}$ nuclear magnetic resonance spectroscopy (TD-NMR) can be a useful tool for assessing the lipid portion of such matrices. In this work, a TD-NMR method was developed and validated to assess the oil content directly from Brazil nuts following the ISO 10565:1998 and DOQ-CGCRE-008. Full validation was addressed covering the working range from 0.67 to $25.00 \mathrm{~g}$ (coefficient of determination, $\mathrm{R}^{2}=0.9993$ ). Limits of detection (LOD) and quantification (LOQ) were 0.20 and $0.67 \mathrm{~g}$, respectively. The repeatability and intermediate precision assays met the guide requirements. Oil contents obtained in two laboratories (different equipment) were statistically similar $(66.93 \pm 4.69$ and $70.13 \pm 4.15 \%)$, highlighting the method's robustness. The developed approach has the potential to be adopted as an industrial reference method for in situ monitoring of Brazil nuts oil contents.
\end{abstract}

Keywords: Bertholletia excelsa, oil quantification, validation, Soxhlet, low-field NMR, quality

\section{Introduction}

Brazil nuts (Bertholletia excelsa Bonpl.) are an economically valuable product mainly originating in the Brazilian, Peruvian, and Bolivian Amazon. Considered the main extractive product exported by Brazil, these nuts stand out due to their chemical composition, which is characterized by a high content of proteins, unsaturated lipids, carbohydrates, essential minerals (notably, selenium), and vitamins. ${ }^{1-3}$ The nutritional value and pleasant taste of Brazil nuts (in natura) have also gained international popularity.

The oil present in these nuts is typically obtained by a hydraulic press and used for culinary purposes or in the cosmetic industry. ${ }^{4}$ Other Brazil nuts-based products, such

*e-mail: alandiegormn@gmail.com; marcosmachado@ufam.edu.br as Brazil nut milk, mix nut confectionaries, cereals bars, chocolate, and the meal of flour preparations, can also be found in the market. ${ }^{3,5}$ After the oil extraction, the oilseed by-product (cake) can still be exploited in the food industry by offering an extract called "milk", as well as proteins concentrated and isolated from the defatted cake. ${ }^{3}$

Current methods performed in Brazil nut extraction increase the potential for contamination with consequent risk to consumer health and thus has led to a crisis in consumer confidence. ${ }^{2}$ For instance, the presence of aflatoxins, produced by fungi (e.g., Aspergillus flavus, A. nomius, and A. parasiticus) has been shown to be associated with human liver cancer. ${ }^{2,3,6}$ Furthermore, the natural germination of Brazil nut trees is difficult and timeconsuming, contributing to its classification as vulnerable to extinction. ${ }^{7}$ With that scenario, a greater demand has arisen regarding the quality of this product, including the 
evaluation of physical, chemical, and biological aspects of the raw material.

Methods capable of assessing the chemistry of intact Brazil nuts and their by-products (e.g., oil and cake) have become essential since they can help to monitor the quality of the final and intermediate products throughout the production chain. The chemistry of Brazil nuts oil has been characterized by a high content of unsaturated fatty acids. ${ }^{8}$ More than $70 \%$ of the oil is composed of triglycerides with the position of fatty acids (palmitic, oleic, and linoleic acids) on the glycerol structure. ${ }^{9}$ Tocopherol, phytosterols, and phenolic compounds have also been reported in this oilseed and, along with its fatty acids and selenium content, are responsible for the nutritional and functional relevance of Brazil nuts. ${ }^{1,10,11}$

Regarding the chemical aspects, the Brazilian Health Regulatory Agency (ANVISA) advocates that the quality control of the oil from Brazil nuts should be performed by the evaluation of acid and peroxide indexes. ${ }^{12}$ The peroxide index has shown to be a very important parameter since it measures the initial oxidative state of the oil expressed in active oxygen per kilogram of oil equivalent. ${ }^{13}$ Furthermore, the saponification index, refraction, and density are often investigated.

Usually, the analyses of nut oils require the use of extraction methods as cold pressing and organic solventbased methods. ${ }^{14}$ Such approaches might lead to small yields or sample degradation. To overcome these problems, techniques that comply with the Green Chemistry principles have gained popularity, such as the supercritical fluid extraction (SFE) $)^{15}$ and time domain nuclear magnetic resonance (TD-NMR). This latter has been shown to be a suitable alternative to assess oil content directly from nuts. ${ }^{14}$

As robust, fast, non-destructive, cost-effective, and versatile tool, with potential for online and in situ measurements, TD-NMR has been widely employed in the food quality control and quality assurance. ${ }^{16-21}$ In the last two decades, TD-NMR applications have expanded to basic food studies, including water status, water compartmentalization, and molecular mobility through relaxation and diffusion measurements. ${ }^{22}$

TD-NMR analyses are based on intensity of free induction decay (FID) and spin echo signals, transverse and longitudinal relaxation times ( $T_{1}$ and $T_{2}$, respectively) and molecular diffusion (D). ${ }^{23}$ The TD-NMR allows acquiring information on the proton density of the solid and liquids components. The nuts solid components like proteins and carbohydrates can be determined using probes with very small dead time (less than $10 \mu \mathrm{s}$ ) and solid echo sequences such as magic sandwich echo (MSE) and Rhim and Kessemeier-radiofrequency optimized solid-echo
(RK-ROSE).$^{24}$ On the other hand, liquid components such as vegetable oil or mobile water content can be measured with standard probe using FID or spin-echo signals. ${ }^{25}$

Following the method proposed by ISO 10565:1998 ${ }^{14}$ (the spin echo pulse sequence: $90^{\circ}-\tau-180^{\circ}$ ), the maximum amplitude of the FID acquired during the first step of the experiment (after the $90^{\circ}$ pulse) is proportional to the number of protons from the water and oil phases of the sample. After a time $\tau_{1}$ and $180^{\circ}$ pulse a spin-echo signal is refocalized and reach the maximum amplitude at another time $\tau_{2}$, where $\tau_{1}=\tau_{2}$ and is proportional only to the oil content. ${ }^{14}$ Because of that, TD-NMR can be used for measuring the oil and fat quantity in several matrices, including directly from seeds. ${ }^{25-27}$ In this context, this work aimed to develop and validate a method for assessing the oil content of B. excelsa nuts in natura via TD-NMR.

\section{Experimental}

\section{Sample acquisition}

Brazil nuts were donated by Prof Dr Ariane Mendonça Kluczkovski from Faculty of Pharmaceutical Sciences of Federal University of Amazonas (UFAM), who acquired the samples from a processing plant located in the State of Pará (Brazil). The oil was extracted from $904 \mathrm{~g}$ of Brazil nuts through cold pressing, using a hydraulic press Tecnal TE-098 (Piracicaba, Brazil). The amount of oil extracted was measured in a beaker $(500 \mathrm{~mL})$, transferred to an amber bottle and kept at room temperature $\left(25^{\circ} \mathrm{C}\right)$. After the decantation of residues, the clear layer was transferred to another amber bottle and kept at room temperature. The resulting oil was used to build the analytical curves. For the application of the TD-NMR method and the exhaustive extraction, in natura Brazil nuts were selected, weighed, and analyzed to find the oil content in percentage (mass/mass).

\section{NMR experiments}

TD-NMR experiments were performed on a SpecFIT Spectrometer (Fine Instrument Technology (FIT), São Carlos, Brazil, spectrometer No. 1), equipped with a permanent magnet of $0.33 \mathrm{~T}$ and a $40 \mathrm{~mm}$ diameter probe, and SLK-200 NMR spectrometer (Spinlock Magnetic Resonance Solution, Cordoba, Argentina, spectrometer No. 2), equipped with a permanent magnet of $0.23 \mathrm{~T}$ and a $38 \mathrm{~mm}$ diameter probe, observing ${ }^{1} \mathrm{H}$ at $15 \mathrm{MHz}$ (spectrometer No. 1) and $10 \mathrm{MHz}$ (spectrometer No. 2). The data were acquired by spin-echo pulse sequence with 64 scans, $90^{\circ}$ pulse length of $14.0 \mu$ s, dead time of $20.0 \mu$ s, $\tau_{1}$ of $3,300 \mu$ s with the acquisition time started at $2,800 \mu$ s, 
$180^{\circ}$ pulse length of $28.0 \mu \mathrm{s}$, and recycle delay (RD) of $1.0 \mathrm{~s}$. The spectra were registered with 1,024 data points (Figure 1). During analyses, the sample temperature and the humidity were kept at $33 \pm 2{ }^{\circ} \mathrm{C}$ and $63 \pm 3 \%$, respectively. The total experimental time lasted around $64 \mathrm{~s}$ for each sample, without including the time used for the sample preparation. Spectrometer No. 2 was used for applying the method in a second laboratory. The pulse lengths were weekly calibrated. For determining $\tau_{1}$, experimental measures were obtained varying $\tau_{1}$ from 2,100 to $3,500 \mu \mathrm{s}$, and the maximal intensity was achieved when $\tau_{1}$ was $2,300 \mu$ s.

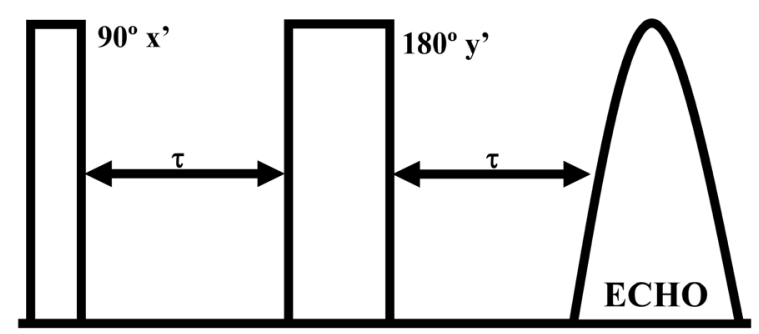

Figure 1. Diagram of the spin-echo pulse sequence.

\section{Method validation}

The method performance parameters were evaluated following the guidelines on validation of chemical test methods DOQ-CGCRE-008 from the National Institute of Metrology, Quality and Technology (INMETRO) of Brazil. $^{28}$

\section{Linearity and linear working range}

Initially, an assay using different amounts of Brazil nuts oil was performed to build a preliminary analytical curve (0.04-46 g). Such a screening test allowed verifying the relation between the instrument's response and the oil amount and to planning the evaluation of the other validation parameters. Grubbs and Cochran's tests were performed to investigate the presence of outliers and the equality of variances. The analytical curves were then built, and analysis of variance (ANOVA) employed the $F$-test investigated their linearity. Also, the residual analysis was performed to investigate the randomness of the data.

The working range was defined only after establishing the limits of quantification and detection. The linear working range was determined from the working range curve observing the exact point where the curve lost the linear response. The sensitivity of the curves built all over the study was monitored by their slopes.

\section{Calibration curve}

Different amounts of Brazil nuts oil were weighted (2.00-16.00 g) and analyzed via TD-NMR. Samples were prepared and analyzed in seven replicates. The presence of outliers was verified by means of Grubbs and Cochran's tests. The analytical curve was built using the intensity of the signal versus the oil amount. The linearity of the curve was tested via ANOVA using the $F$-Snedecor test. Also, residuals were calculated to determine bias. The statistical tests were performed using Minitab ${ }^{\circledR}$ software (18.1). ${ }^{29}$

Limit of detection (LOD) and limit of quantification (LOQ)

The noise intensity was measured by acquiring seven spectra of an empty NMR tube. The average and the standard deviation of those measurements were used to calculate the theoretical LOD and LOQ through equations 1 and 2 , respectively.

$\mathrm{LOD}=\mathrm{X}+\mathrm{t} \times \mathrm{s}$
$\mathrm{LOQ}=\mathrm{X}+10 \times \mathrm{s}$

where $\mathrm{X}$ is the average of the noise intensity found in the spectra, $s$ is its standard deviation, and $t$ is from the Student's $t$-distribution. After that, TD-NMR spectra were acquired using Brazil nut oil quantities above and below the theoretical LOD. The final LOD was defined by interpolating signal intensities in the analytical curve, as well as by comparing the standard deviations of each measurement. Once the LOD was set, samples containing the minimum oil weighed $(n=6)$ were prepared to verify if they could be detected and differentiated from the noise of spectra.

\section{Precision}

For the precision test, seven analytical curves were built using a range from 3.00 to $23.00 \mathrm{~g}$ of oil.

\section{Repeatability}

The method repeatability was investigated by two analysts using two spectrometers. They independently built six analytical curves in six different days using the developed method, in a total of 12 analytical curves. Only curves acquired by the same analyst had their performances compared. Relative standard deviation (RSD) was used to evaluate the repeatability as established by the Association of Official Analytical Chemists (AOAC). ${ }^{30}$ As the results were expressed in grams, the masses used were normalized to define the acceptance range.

\section{Intermediate precision}

The intermediate precision was evaluated intra-day (six analytical curves were built) and inter-day (eight analytical curves were built) by two analysts. The presence of outliers was investigated via Grubbs's test. RSD of the intermediate 
precision, at different time and analysts, was calculated using equation 3 ( $\mathrm{Spi}_{\text {(то.). }}$ ). ANOVA analysis was used to verify the statistical equivalence of the analytical curves built by the two analysts.

$\operatorname{Spi}_{\text {(т.O.) }}=\sqrt{\frac{1}{\mathrm{~m}(\mathrm{n}-1)} \sum\left(\mathrm{y}_{\mathrm{jk}}-\mathrm{y}\right)^{2}}$

where $m$ is the total number of samples, $n$ is the number of replicates, $\mathrm{y}_{\mathrm{jk}}$ is the individual result of each sample, and $\mathrm{y}$ the average of results for each sample.

\section{Precision limit (PL)}

PL allow the monitoring of significant differences at a given confidence level. For determining PL, equation 4 was employed.

Precision limit $=\mathrm{t} \times \sqrt{2} \times \mathrm{s}$

where $t$ is related to the abscissa value of the bilateral Student's $t$-distribution, with a confidence interval of $95.35 \%, \sqrt{2}$ reflects the difference of two measures, and $\mathrm{s}$ is the RSD calculated from the repeatability, reproducibility, or intermediate precision tests.

According to INMETRO, for cases where there is no comparative method evaluable, the HORRAT equation can be used to evaluate the acceptance of the aspects studied in the newly developed method (equation 5).

HORRAT $=\frac{\text { RSDr }}{\text { PRSDr }}$

where RSDr is the RSD of the parameter of precision studied and PRSDr is the predicted reproducibility obtained from the Horwitz equation.

In the present work, the predicted reproducibility obtained from the Horwitz equation was 2. If the value found was lower or equal to 2 , the results were considered satisfactory. Besides that, the interaction analysis of principal effects explored in the experiments (equipment, analyst, day, period, and weight) was performed using the main effects graph obtained by ANOVA. To do that, Minitab $^{\circledast} 18.1$ software was employed. ${ }^{29}$

\section{Convectional extraction of oil content by Sohxlet method}

The convectional extraction of oil from fifteen Brazil nut almonds, previously submitted to TD-NMR analyses, was carried out using a Soxhlet type extractor (Model LUCA-201/6-E from Lucaderma, São José do Rio Preto, Brazil). These nuts were pulped, hand-crushed, weighed, and wrapped with filter paper, and were divided into three groups containing five almonds each. Each almond of these three groups was individually subjected to exhaustive extraction with $n$-hexane ( $200 \mathrm{~mL}$ each, HPLC grade, Tedia Co Inc, Fairfield, USA) for 6, 8, or $10 \mathrm{~h}$, respectively. After the extractions, the samples were concentrated on a rotary evaporator (Fisatom 801, São Paulo, Brazil) at $40^{\circ} \mathrm{C}$. The obtained oils were subjected to centrifugation (Hettich RotoFix 32A model, Tuttlingen, Germany) at 4,000 rpm $(2,862 \mathrm{G}$-force) for $30 \mathrm{~min}$. The superior phase of samples was separated, dried in a desiccator, and weighed. After finding normality, ANOVA (One-Way, Tukey's test, $95 \%$ significance) and T-test $(p<0.05)$ were performed. The results obtained were expressed as mean \pm standard deviation of mass ratio. Minitab ${ }^{\circledR} 18.1$ software was employed in these analyses. ${ }^{29}$

\section{Results and Discussion}

The oxidation condition of oils investigated was previously assessed by the acid and peroxide indexes, as required by ANVISA. ${ }^{12}$ The values found for the samples were satisfactory and enabled their use to develop the TD-NMR method (see Supplementary Information (SI) section).

Verification of parameters of validation

\section{Selectivity}

The method's selectivity was ensured by the ISO 10565:1998, which determines the pulsed NMR suitable to assess the oil contents of commercial oilseeds once the samples have a water content less than $10 \% .^{14}$

\section{LOD and LOQ}

The noise intensity approach led to LOD and LOQ values of 0.16 and $0.35 \mathrm{~g}$, respectively. However, based on the study of the curve performance to masses near to those values, one can be observed that LOD and LOQ were 0.20 and $0.67 \mathrm{~g}$, respectively; since for values lower than $0.20 \mathrm{~g}$, RSD was higher than $10 \%$ and, for masses higher than $0.67 \mathrm{~g}$ RSD was lower than $4 \%$ (Table S1, SI section). It is worth mentioning that INMETRO advocates RSD values $\leq 5 \% .{ }^{31}$

These results can be corroborated when verifying the analytical curve (Figure S1, SI section). The minimum point that can be differentiated from the blank value with reliability was $0.20 \mathrm{~g}$. Figure $\mathrm{S} 1$ also shows the region with the signals mostly influenced by equipment noises. In addition, after $0.67 \mathrm{~g}$ the minimum value of dispersion was achieved regarding the trend line drawn (Figure S2, SI section). 
The final magnitude of LOD and LOQ were achieved when sextuplicate samples, with the values 0.20 and $0.67 \mathrm{~g}$, were analyzed resulting in RSD of 7.46 and $2.67 \%$, respectively. Also, LOQ was found to have good accuracy with $98 \%$ of recuperation, which fulfills INMETRO requirements $(98-102 \%){ }^{28}$

\section{Linearity and linear working range}

The linear working range was built after investigating the preliminary analytical curve (sub-section "Linearity and linear working range" in the Experimental section) and determined using the LOQ and LOD. Several spectra were acquired using different oil amounts, from the LOD until the saturation of the equipment (Figure S2). A total of 39 points were measured and all samples were prepared and analyzed in triplicate. Thus, calibration curves used for assessing the oil content in in natura Brazil nuts ranged from 0.67 to $25.09 \mathrm{~g}$ and their analytical performances were ensured by the investigation of the validation parameters. The quality of the data used to build the analytical curve was checked by ANOVA, which showed a good correlation of the results and the normal characteristic of the data distribution by the analysis of histogram residues (Figure S3, SI section). The analysis of the residual plot (predicted values vs. actual values) revealed the random character of the data, which is in line with INMETRO requirements (Figure S4, SI section). The linearity of the analytical curve was then confirmed (coefficient of determination, $\mathrm{R}^{2}=0.9993$ ) with no presence of outliers (Figure S5, SI section).

\section{Repeatability}

RSD values found in the method repeatability assay were less than $5 \%$, as required by INMETRO..$^{28}$ Also, HORRAT test showed values lower than $2 \%$ for all points evaluated (Table 1). The analytical curve built by the two analysts were reproducible and had excellent linear coefficients (Figure S6, SI section). Analytical recuperation values were evaluated for all curves and they were in line with the range advocated by INMETRO (98-102\%).

Table 1. Repeatability study performed by two analysts in six different days using two spectrometers

\begin{tabular}{|c|c|c|c|c|c|c|c|c|}
\hline & Ave. exp. mass & Ave. the. mass & $\begin{array}{c}\text { Normalized } \\
\text { mass / \% }\end{array}$ & SD & Exp. RSD & Allowed RSD & PL / \% & HORRAT \\
\hline \multirow{12}{*}{$\begin{array}{l}\text { Spectrometer } \\
\text { No. } 1\end{array}$} & \multicolumn{8}{|c|}{ Analyst No. 1} \\
\hline & 3.009 & 3.004 & 13 & 0.04 & 1.3 & $\geq 1.3$ & 3.66 & 0.65 \\
\hline & 7.918 & 8.007 & 34 & 0.09 & 1.2 & $\geq 1.3$ & 3.25 & 0.58 \\
\hline & 13.103 & 13.012 & 57 & 0.13 & 1.0 & $\geq 1.3$ & 2.86 & 0.51 \\
\hline & 17.903 & 18.015 & 78 & 0.13 & 0.7 & $\geq 1.3$ & 2.01 & 0.36 \\
\hline & 22.983 & 23.018 & 100 & 0.17 & 0.7 & $\geq 1.3$ & 2.09 & 0.37 \\
\hline & \multicolumn{8}{|c|}{ Analyst No. 2} \\
\hline & 3.009 & 3.002 & 13 & 0.04 & 1.2 & $\geq 1.3$ & 3.37 & 0.60 \\
\hline & 7.906 & 8.004 & 34 & 0.04 & 0.5 & $\geq 1.3$ & 1.48 & 0.26 \\
\hline & 13.107 & 13.007 & 57 & 0.08 & 0.6 & $\geq 1.3$ & 1.76 & 0.31 \\
\hline & 18.076 & 18.009 & 79 & 0.08 & 0.4 & $\geq 1.3$ & 1.17 & 0.21 \\
\hline & 22.936 & 23.012 & 100 & 0.05 & 0.2 & $\geq 1.3$ & 0.63 & 0.11 \\
\hline \multirow{12}{*}{$\begin{array}{l}\text { Spectrometer } \\
\text { No. } 2\end{array}$} & \multicolumn{8}{|c|}{ Analyst No. 1} \\
\hline & 1.877 & 2.008 & 10 & 0.01 & 0.8 & $\geq 1.3$ & 2.14 & 0.38 \\
\hline & 6.052 & 6.023 & 34 & 0.00 & 0.1 & $\geq 1.3$ & 0.15 & 0.03 \\
\hline & 8.135 & 8.031 & 45 & 0.00 & 0.0 & $\geq 1.3$ & 0.08 & 0.02 \\
\hline & 14.245 & 14.054 & 80 & 0.01 & 0.0 & $\geq 1.3$ & 0.14 & 0.02 \\
\hline & 17.885 & 18.067 & 100 & 0.04 & 0.2 & $\geq 1.3$ & 0.61 & 0.11 \\
\hline & \multicolumn{8}{|c|}{ Analyst No. 2} \\
\hline & 1.904 & 2.034 & 11 & 0.01 & 0.5 & $\geq 1.3$ & 1.35 & 0.24 \\
\hline & 6.079 & 6.053 & 34 & 0.00 & 0.0 & $\geq 1.3$ & 0.02 & 0.00 \\
\hline & 8.176 & 8.063 & 46 & 0.01 & 0.1 & $\geq 1.3$ & 0.17 & 0.03 \\
\hline & 14.299 & 14.087 & 80 & 0.01 & 0.1 & $\geq 1.3$ & 0.28 & 0.05 \\
\hline & 17.925 & 18.103 & 100 & 0.00 & 0.0 & $\geq 1.3$ & 0.06 & 0.01 \\
\hline
\end{tabular}

Ave. exp. mass: average experimental mass; Ave. the. mass: average theoretical mass; SD: standard deviation; Exp. RSD: experimental relative standard deviation; Allowed RSD: allowed relative standard deviation; PL: precision limit; HORRAT: value found using equation 5. 


\section{Intermediate precision}

The intermediate precision curves showed satisfying

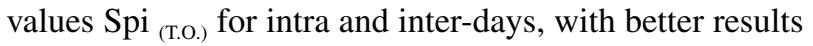
found to the latter. No outliers were found as can be seen in Figure S7 (SI section). The acceptability parameters calculated are depicted in Table 2. Furthermore, the statistical equivalence of the analytical curves built for both analysts and in different days was confirmed by ANOVA, proving that the developed method has a good precision and accuracy even when it is reproduced by different operators (Figure S8, SI section).

Table 2. The acceptability parameters calculated to the intra and interdays analyses. The experiments were performed in two spectrometers

\begin{tabular}{|c|c|c|c|}
\hline & Average mass / g & $\mathrm{Spi}_{\text {(т.о.) }} / \%$ & $\mathrm{PL} / \%$ \\
\hline \multirow{12}{*}{$\begin{array}{l}\text { Spectrometer } \\
\text { No. } 1\end{array}$} & \multicolumn{3}{|c|}{ Intra-day } \\
\hline & 3.003 & 0.4 & 1.3 \\
\hline & 8.006 & 0.3 & 0.7 \\
\hline & 13.009 & 0.4 & 1.1 \\
\hline & 18.012 & 0.4 & 1.1 \\
\hline & 23.015 & 0.3 & 0.9 \\
\hline & \multicolumn{3}{|c|}{ Inter-day } \\
\hline & 3.003 & 1.2 & 3.4 \\
\hline & 8.006 & 0.6 & 1.7 \\
\hline & 13.009 & 0.8 & 2.2 \\
\hline & 18.012 & 0.7 & 2.0 \\
\hline & 23.015 & 0.6 & 1.7 \\
\hline \multirow{12}{*}{$\begin{array}{l}\text { Spectrometer } \\
\text { No. } 2\end{array}$} & \multicolumn{3}{|c|}{ Intra-day } \\
\hline & 2.016 & 0.5 & 1.3 \\
\hline & 6.037 & 0.2 & 0.5 \\
\hline & 8.048 & 0.1 & 0.4 \\
\hline & 14.074 & 0.1 & 0.3 \\
\hline & 18.091 & 0.1 & 0.4 \\
\hline & \multicolumn{3}{|c|}{ Inter-day } \\
\hline & 2.015 & 0.5 & 1.3 \\
\hline & 6.035 & 0.2 & 0.5 \\
\hline & 8.044 & 0.2 & 0.5 \\
\hline & 14.064 & 0.2 & 0.4 \\
\hline & 18.079 & 0.2 & 0.5 \\
\hline
\end{tabular}

$\mathrm{Spi}_{\text {(т.).) }}$ : value found using equation 3 ; PL: precision limit.

\section{Application of the method}

Signal intensities from Brazil nuts were interpolated in the analytical curve to obtain their oil contents. Table 3 depicts the results for two sample sets analyzed in two laboratories. For analyst No. 1 and spectrometer No. 1 the average oil content was $66.93 \pm 4.69 \%$ with values ranging from 56.59 to $75.07 \%$, while for analyst No. 2 and spectrometer No. 2 the average value reported was
$70.13 \pm 4.15 \%$ with the oil amounts varying from 61.35 to $75.68 \%$. As shown, these results are quite similar and give a good indication of the robustness of the method.

Table 3. Brazil nuts oil contents determined by two analysts in different spectrometers using the newly developed method

\begin{tabular}{|c|c|c|}
\hline \multirow[b]{2}{*}{ Sample } & \multicolumn{2}{|c|}{ Oil content / \% } \\
\hline & $\begin{array}{l}\text { Analyst No. } 1 \text { and } \\
\text { equipment No. } 1\end{array}$ & $\begin{array}{l}\text { Analyst No. } 2 \text { and } \\
\text { equipment No. } 2\end{array}$ \\
\hline 1 & 69.39 & 71.07 \\
\hline 2 & 75.07 & 71.94 \\
\hline 3 & 62.28 & 66.52 \\
\hline 4 & 65.86 & 72.74 \\
\hline 5 & 69.41 & 75.49 \\
\hline 6 & 70.90 & 67.34 \\
\hline 7 & 69.03 & 68.19 \\
\hline 8 & 56.59 & 66.99 \\
\hline 9 & 66.91 & 65.04 \\
\hline 10 & 66.86 & 73.79 \\
\hline 11 & 71.43 & 61.35 \\
\hline 12 & 63.87 & 75.68 \\
\hline 13 & 67.99 & 69.32 \\
\hline 14 & 68.30 & 72.68 \\
\hline 15 & 60.07 & 73.75 \\
\hline Average & 66.93 & 70.13 \\
\hline RSD & 4.69 & 4.15 \\
\hline
\end{tabular}

RSD: relative standard deviation.

The TD-NMR method performance was compared to the conventional Soxhlet extraction, which is a well-known destructive, time consuming, and laborious method. Also, Soxhlet extraction requires to determine the time for the exhaustive extraction. Because of that, three extraction times were evaluated $(6,8$, and $10 \mathrm{~h})$. ANOVA of the oil contents obtained from the Soxhlet extraction at three different times showed that there is no statically significant difference between the extraction times (Figure S9, SI section). Therefore, the general average of the oil content obtained with the Soxhlet method was $55.2 \pm 5.0 \%$.

The different results found by the two approaches might be a consequence of the incomplete extraction of lipids by the Soxhlet method. To confirm that hypothesis, the oil content of cakes (Brazil nuts waste), saved after the exhaustive extraction, were analyzed via TD-NMR, showing a mean value of $14.9 \pm 6.4 \%$ (Figure S10, SI section). This result showed that the lipid portion retained in the cake is significant and the oil contents determined by the Soxhlet method were underestimated. When the oil content values found by exhaustive extraction were added to the oil content of the Brazil nuts waste value 
of $70.2 \pm 6.1 \%$ was found, which is statically equal to outcomes acquired by TD-NMR method, T-test, $p<$ 0.05 (Figure S11, SI section). Niu et al. ${ }^{32}$ compared the performance of TD-NMR method and Soxhlet extraction for determining oil contents in Sacha inchi. Higher accuracy and efficiency were observed when TD-NMR was used. Soxhlet method requires multiple steps (e.g., solvent removal and extracted oil weighing) and this might contribute to discordances between results.

Amounts of Brazil nuts oil obtained TD-NMR method reproduced the tendency described in literature, which in turn has ranged between 60-70\%., ${ }^{3,10,11,15}$ However, the present study reports the first oil quantification directly from Brazil nuts.

\section{Conclusions}

TD-NMR method proved to be an improvement on traditional Brazil nut oil content analysis. TD-NMR does not need an extraction using harsh organic solvents and it can be performed in a shorter time. This method was validated based on the DOQ-CGCRE-008, and the results found over the validation process fulfill the INMETRO requirements. The application of the method was performed in two laboratories (different equipment) and led to similar values of oil contents: $66.93 \pm 4.69$ and $70.13 \pm 4.15 \%$, for laboratory 1 and 2, respectively. These values were higher than those found when conventional extraction was used, which highlights the drawback of such a method. The simplicity and possibility of automation of TD-NMR spectroscopy make this approach quite promising for in situ monitoring the Brazil nuts oil content through the production chain, which might help to ensure the product's quality.

\section{Supplementary Information}

Supplementary data are available free of charge at http://jbcs.sbq.org.br as a PDF file.

\section{Acknowledgments}

The authors would like to thank Coordenação de Aperfeiçoamento de Pessoal de Nível Superior (CAPES), Financiadora de Estudos de Projetos e Programas (FINEP) and Analytical Center of UFAM for financial support, fellowships, and infrastructure, and Dr Vinci Hung and Dr Hussain Masoom, for the critical reading and revision of the manuscript, and Katlin Suellen Rech, for the artistic concept of the graphical abstract.

\section{Author Contributions}

Úrsula A. Ribeiro was responsible for conceptualization, methodology, validation, investigation, formal analysis, and writing original draft; Leonardo C. Queiroz for validation, formal analysis, and investigation; Gabriel A. Barros for investigation; Agide G. Marassi for validation; André S. Carvalho for resources; Daniel M. Consalter for resources; Jaqueline A. Bezerra for investigation and resources; Alan D. C. Santos for visualization and writing-review and editing; Luiz Alberto Colnago for conceptualization, resources, visualization, and writing-review and editing; Marcos B. Machado for supervision, writing-review and editing, formal analysis, conceptualization, and methodology.

\section{References}

1. Costa, P. A. D.; Ballus, C. A.; Teixeira-Filho, J.; Godoy, H. T.; Food Res. Int. 2010, 43, 1603.

2. Manual de Segurança e Qualidade para a Cultura da Castanhado-Brasil; Embrapa Informação Tecnológica: Brasília, 2004, available at https://ainfo.cnptia.embrapa.br/digital/bitstream/ item/18218/1/MANUALSEGURANCAQUALIDADEParaa culturadacastanhadoBrasil.pdf, accessed in March 2021.

3. Freitas-Silva, O.; Venâncio, A.; Food Res. Int. 2011, 44, 1434.

4. Pacheco, A. M.; Scussel, V. M.; Castanha do Brasil-da Floresta Tropical ao Consumidor; Editograf: Florianópolis, Brazil, 2006.

5. Souza, M. L. D.; Menezes, H. C. D.; Food Sci. Technol. 2004, 24, 120.

6. Arrus, K.; Blank, G.; Abramson, D.; Clear, R.; Holley, R. A.; J. Stored Prod. Res. 2005, 41, 513.

7. International Union for Conservation of Nature (IUCN); The IUNC Red List of Threatened Species, version 2020.1, available at https://www.iucnredlist.org/species/32986/9741363, accessed in March 2021.

8. Rodrigues, J. E.; Araújo, M. E.; Azevedo, F. F. M.; Machado, N. T.; J. Supercrit. Fluids 2005, 34, 223.

9. Holčapek, M.; Jandera, P.; Zderadička, P.; Hrubá, L.; J. Chromatogr. A 2003, 1010, 195.

10. Santos, O. V.; Corrêa, N. C. F.; Carvalho, R. N.; Costa, C. E. F.; França, L. F. F.; Lannes, S. C. S.; Food Res. Int. 2013, 51, 841.

11. Yang, J.; LWT-Food Sci. Technol. 2009, 42, 1573.

12. Agência Nacional de Vigilância Sanitária (ANVISA); Resolução da Diretoria Colegiada (RDC) No. 270, 22/09/2005, available at bvsms.saude.gov.br/bvs/saudelegis/anvisa/2005/ rdc0270_22_09_2005.html\#: :text=Regulamento\%20 Técnico\%20de\%20Procedimentos\%200peracionais, Brasília\%2C\%20DF\%2C\%2006\%20nov, accessed in March 2021. 
13. Ramalho, V. C.; Jorge, N.; Quim. Nova 2006, 29, 755.

14. ISO 10565:1998: Oilseeds-Simultaneous Determination of Oil and Water Contents-Method Using Pulsed Nuclear Magnetic Resonance Spectrometry, ISO: Geneva, 1998.

15. Zanqui, A. B.; da Silva, C. M.; Ressutte, J. B.; de Morais, D. R.; Santos, J. M.; Eberlin, M. N.; Cardozo-Filho, L.; Visentainer, J. V.; Gomes, S. T. M.; Matsushita, M.; J. Braz. Chem. Soc. 2020, 31,603 .

16. Colnago, L. A.; Moraes, T. B.; Monaretto, T.; Andrade, F. D. In Magnetic Resonance in Food Science: Defining Food by Magnetic Resonance; Capozzi, F.; Laghi, L.; Belton, P. S., eds.; The Royal Society of Chemistry: London, UK, 2015, p. 1-16.

17. Santos, P. M.; Corrêa, C. C.; Forato, L. A.; Tullio, R. R.; Cruz, G. M.; Colnago, L. A.; Food Control 2014, 38, 204.

18. Castell-Palou, A.; Rosselló, C.; Femenia, A.; Bon, J.; Simal, S.; J. Food Eng. 2011, 104, 525.

19. Ribeiro, R. O. R.; Mársico, E. T.; Carneiro, C. S.; Monteiro, M. L. G.; Conte Jr., C. A.; Mano, S.; de Jesus, E. F. O.; LWT-Food Sci. Technol. 2014, 55, 90.

20. Salomonsen, T.; Sejersen, M. T.; Viereck, N.; Ipsen, R.; Engelsen, S. B.; Int. Dairy J. 2007, 17, 294.

21. Zhang, Q.; Saleh, A. S. M.; Shen, Q.; Food Bioprocess Technol. 2013, 6, 2562.

22. Todt, H.; Guthausen, G.; Burk, W.; Schmalbein, D.; Kamlowski, A.; Food Chem. 2006, 96, 436.

23. Flores, D. W. M.; Colnago, L. A.; Ferreira, M. D.; Spoto, M. H. F.; Microchem. J. 2016, 128, 113.

24. Garcia, R. H. S.; Filgueiras, J. G.; de Azevedo, E. R.; Colnago, L. A.; Solid State Nucl. Magn. Reson. 2019, 104, 101619.
25. Pedersen, H. T.; Munck, L.; Engelsen, S. B.; J. Am. Oil Chem. Soc. 2000, 77, 1069.

26. da Rocha, G.; Colnago, L. A.; Moraes, T. B.; Zagonel, G. F.; de Muniz, G. I. B.; Peralta-Zamora, P. G.; Barison, A.; Energy Fuels 2017, 31, 5120.

27. Santos, O. N. A.; Folegatti, M. V.; Dutra, L. M.; Andrade, I. P. S.; Fanaya Jr., E. D.; Lena, B. P.; Barison, A.; Santos, A. D. C.; Ind. Crops Prod. 2017, 109, 918.

28. Instituto Nacional de Metrologia, Normalização e Qualidade Industrial (INMETRO); DOQ-CGCRE-008, Orientações sobre Validação de Métodos Analíticos, INMETRO: Rio de Janeiro, 2016, available at http://www.inmetro.gov.br/Sidoq/Arquivos/ Cgcre/DOQ/DOQ-Cgcre-8_05.pdf, accessed in March 2021.

29. Minita $^{\circledast}$ 18.1; Minitab Inc., State College, PA, USA, 2017.

30. Association of Official Agricultural Chemists (AOAC); AOAC Peer-Verified Methods Program Manual on Policies and Procedures; AOAC International: Rockville, 1998, available at https://citeseerx.ist.psu.edu/viewdoc/download?doi=10.1.1. 196.7223\&rep=rep1\&type=pdf, accessed in March 2021.

31. Instituto Nacional de Metrologia, Normalização e Qualidade Industrial (INMETRO); International Vocabulary of Metrology: Basic and General Concepts and Associated Terms, $3^{\text {rd }}$ ed.; INMETRO: Duque de Caxias, 2012, available at https://www. bipm.org/utils/common/documents/jcgm/JCGM_200_2012. pdf, accessed in March 2021.

32. Niu, L.; Li, J.; Chen, M.-S.; Xu, Z.-F.; Ind. Crops Prod. 2014 , $56,187$.

Submitted: December 9, 2020

Published online: March 23, 2021 